This is an electronic reprint of the original article. This reprint may differ from the original in pagination and typographic detail.

Author(s): Houghton, Adrian; Hurmalainen, Juha; Mansikkamäki, Akseli; Piers, Warren; Tuononen, Heikki

Title: Direct observation of a borane-silane complex involved in frustrated Lewis-pairmediated hydrosilylations

Year: $\quad 2014$

Version:

Please cite the original version:

Houghton, A., Hurmalainen, J., Mansikkamäki, A., Piers, W., \& Tuononen, H. (2014). Direct observation of a borane-silane complex involved in frustrated Lewis-pairmediated hydrosilylations. Nature Chemistry, 6(11), 983-988.

https://doi.org/10.1038/nchem.2063

All material supplied via JYX is protected by copyright and other intellectual property rights, and duplication or sale of all or part of any of the repository collections is not permitted, except that material may be duplicated by you for your research use or educational purposes in electronic or print form. You must obtain permission for any other use. Electronic or print copies may not be offered, whether for sale or otherwise to anyone who is not an authorised user. 


\section{Direct observation of a borane-silane complex involved in frustrated Lewis-pair-mediated}

\section{hydrosilylations}

Adrian Y. Houghton ${ }^{1}$, Juha Hurmalainen ${ }^{2}$, Akseli Mansikkamäki ${ }^{2}$, Warren E. Piers ${ }^{1}$, ${ }^{*}$ and Heikki

M. Tuononen ${ }^{2 *}$

${ }^{1}$ Department of Chemistry, University of Calgary, 2500 University Drive NW, Calgary, Alberta, T2N 1N4 Canada. *e-mail: wpiers@ucalgary.ca

${ }^{2}$ Department of Chemistry, Nanoscience Center, University of Jyväskylä, P.O. Box 35, FI-40014 Jyväskylä, Finland. *e-mail: heikki.m.tuononen@jyu.fi

Abstract: Perfluorarylborane Lewis acids catalyze the addition of silicon-hydrogen bonds across $\mathrm{C}=\mathrm{C}, \mathrm{C}=\mathrm{N}$ and $\mathrm{C}=\mathrm{O}$ double bonds. This "metal-free" hydrosilation has been proposed to occur via borane activation of the silane $\mathrm{Si}-\mathrm{H}$ bond, rather than through classical Lewis acid/base adducts with the substrate. However, the key borane/silane adduct has never been experimentally observed. Here, it is shown that the strongly Lewis acidic, antiaromatic 1,2,3tris(pentafluorophenyl)-4,5,6,7-tetrafluoro-1-boraindene forms an observable, isolable adduct with triethylsilane. The equilibrium for adduct formation has been studied quantitatively through variable temperature NMR spectroscopic investigations. The interaction of the silane with the borane occurs through the $\mathrm{Si}-\mathrm{H}$ bond, as evidenced by trends in the silicon-hydrogen coupling constant and the IR stretching frequency of the $\mathrm{Si}-\mathrm{H}$ bond, as well as by X-ray crystallography and theoretical calculations. The adduct's reactivity with nucleophiles and its efficacy in the hydrosilation of olefins demonstrate conclusively the role of this species in metal free, "frustrated Lewis pair" hydrosilation reactions. 
Homogeneous catalytic processes necessitating a bond activation step typically require transition metal-based catalysts in order to achieve turnover. Accordingly, many catalysts from metals across the transition period are known that conduct the hydrosilation and/or hydrogenation of unsaturated organic functions such as $\mathrm{C}=\mathrm{O}, \mathrm{C}=\mathrm{N}$ and $\mathrm{C}=\mathrm{C}$ bonds. In such systems, the $\mathrm{Si}-\mathrm{H}$ or $\mathrm{H}-\mathrm{H}$ bonds are activated via oxidative addition or sigma bond metathesis processes at the transition metal center as a key first step in the catalytic cycle. ${ }^{1}$

While such catalysts offer many advantages, two drawbacks are the high cost and toxicity of metals most typically employed in such applications. There has therefore been significant interest in developing highly active, selective catalysts based on more economical and less harmful elements such as first row transition metals ${ }^{2}$ or main group elements. ${ }^{3,4}$ With regard to the latter class of "metal-free" catalysts, the primary challenge lies in coaxing main group element compounds into mediating the critical bond activation step necessary for catalytic turnover. $^{5}$

In this context, our observation in the mid 1990's that the strongly Lewis acidic organoborane tris-pentafluorophenyl borane, $\mathrm{B}\left(\mathrm{C}_{6} \mathrm{~F}_{5}\right)_{3},{ }^{6}$ was a highly active catalyst for the hydrosilation of carbonyl $^{7}$ and imine ${ }^{8}$ functions has proven to be a key discovery in the development of metalfree catalyst systems for the addition of Si- $\mathrm{H}^{9-13}$ and subsequently $\mathrm{H}-\mathrm{H}^{14-16}$ across a number of unsaturated bonds. Although we initially surmised that $\mathrm{B}\left(\mathrm{C}_{6} \mathrm{~F}_{5}\right)_{3}$ was serving to activate the carbonyl group via a classical Lewis acid-Lewis base interaction, kinetic and mechanistic studies strongly suggested that, although such adducts are quite thermodynamically favored, ${ }^{17,18}$ the true role of the borane was to activate the silane, ${ }^{7,19}$ as depicted in Fig. 1. The putative borane-silane adduct $\mathbf{I}$ is then susceptible to attack at silicon by the Lewis basic substrate, resulting in the bond activation intermediate III. This type of bond cleavage has come to be termed "frustrated Lewis 
pair" (FLP) bond activation. ${ }^{20,21}$ In the hydrogenation chemistry, the role of an $\mathrm{H}_{2} \cdot \mathrm{B}\left(\mathrm{C}_{6} \mathrm{~F}_{5}\right)_{3}$ adduct $(\mathbf{I}, \mathrm{E}=\mathrm{H})$ is still in question, ${ }^{22}$ and proposals that involve the formation of a weak "encounter complex" II, stabilized by secondary C-H $\cdots$ F interactions, prior to FLP activation of $\mathrm{H}_{2}$ via III have strong computational support. ${ }^{23,24}$ Whether the path to III involves an $\mathrm{EH} \cdot \mathrm{B}\left(\mathrm{C}_{6} \mathrm{~F}_{5}\right)_{3}$ adduct $\mathbf{I}$ or an encounter complex II, the bond activation transition state leads to an ion pair IV which proceeds to product upon transfer of hydride from the $\left[\mathrm{HB}_{(}\left(\mathrm{C}_{6} \mathrm{~F}_{5}\right)_{3}\right]^{-}$to the substrate carbon, regenerating the $\mathrm{B}\left(\mathrm{C}_{6} \mathrm{~F}_{5}\right)_{3}$ catalyst.
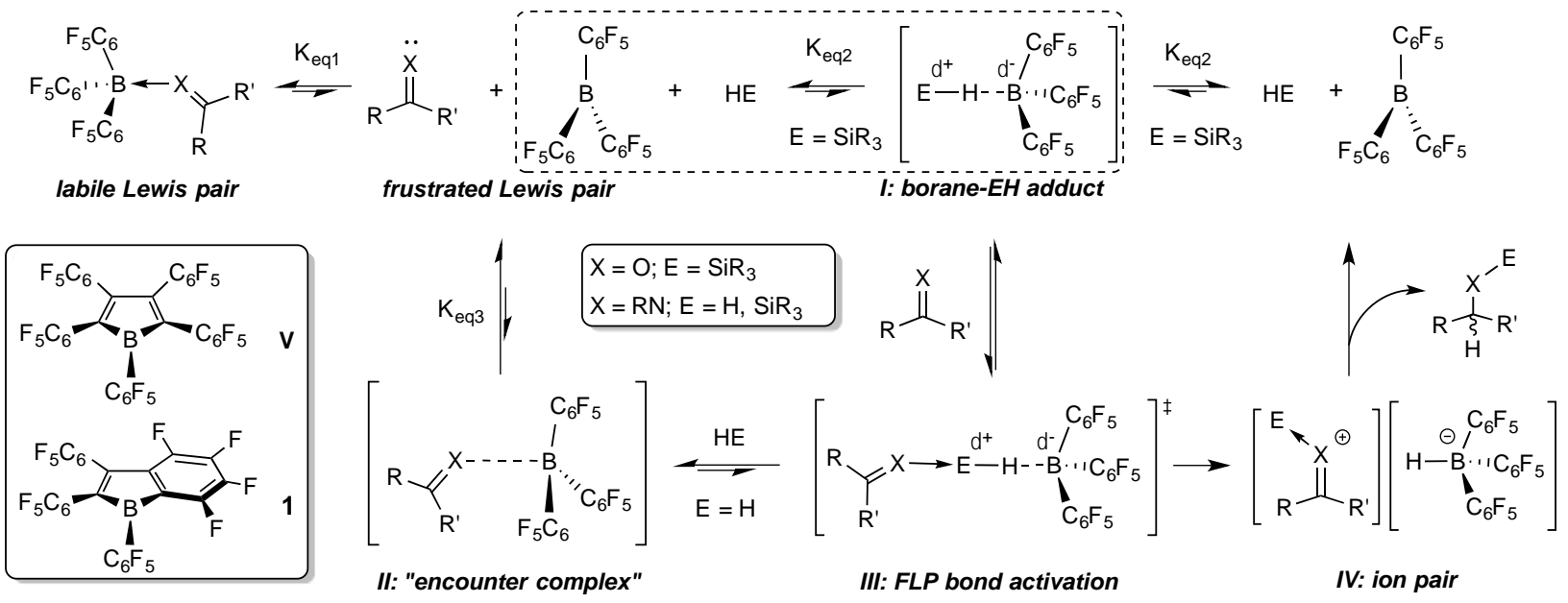

Figure 1. The mechanism of "frustrated" Lewis pair activation of Si-H and H-H bonds. The various important equilibria involved in the activation and cleavage of $\mathrm{Si}-\mathrm{H}$ and $\mathrm{H}-\mathrm{H}$ bonds by Lewis acid/base pairs are depicted. While formation of classical Lewis acid/base adducts ( $\mathrm{K}_{\text {eq1 }}$ ) may be favored, free Lewis acid may also interact with E-H to form a borane/E-H adduct which is the key intermediate in FLP activation of these bonds. This equilibrium, $\mathrm{K}_{\text {eq2 }}$ is highlighted by the box with dashed lines. Such adducts I have not been experimentally observed. Inset: structures of antiaromatic borole $\mathbf{V}$ and boraindene $\mathbf{1}$.

Much experimental and computational ${ }^{25}$ support for this general mechanistic proposal has appeared in the years since our first disclosure of this chemistry. In addition to our own kinetic and labeling investigations, ${ }^{719}$ Oestreich has used stereo pure silanes to elegantly demonstrate that the Walden inversion at silicon that the mechanism predicts via structure $\mathbf{I}$ for $\mathrm{E}=\mathrm{R}_{3} \mathrm{Si}$ is 
indeed operative. ${ }^{26,27}$ Furthermore, in some cases, the ion pair intermediate $\mathbf{I V}$ can be observed spectroscopically. 8,28

This cumulative body of evidence has resulted in a high degree of acceptance for this mechanism in the literature, but the specific nature of the adducts I, or encounter complexes of type II, remain experimentally opaque. ${ }^{22,29}$ It has been observed that $\mathrm{B}\left(\mathrm{C}_{6} \mathrm{~F}_{5}\right)_{3}$ reacts slowly with $\mathrm{Et}_{3} \mathrm{SiH}^{30,31}$ to give bis-pentafluorophenyl borane, $\mathrm{HB}\left(\mathrm{C}_{6} \mathrm{~F}_{5}\right)_{2},{ }^{32}$ along with $\mathrm{Et}_{3} \mathrm{SiC}_{6} \mathrm{~F}_{5}$, a process in which a borane-silane adduct is implicated. However, extensive attempts to detect this adduct through low temperature spectroscopic studies ${ }^{19,33}$ consistently failed to provide convincing evidence for its presence in solution. In other words, $\mathrm{K}_{\mathrm{eq} 2}$ in Scheme 1 appears to strongly disfavor formation of adduct $\mathbf{I}$ for the Lewis acid $\mathrm{B}\left(\mathrm{C}_{6} \mathrm{~F}_{5}\right)_{3}$. We were thus intrigued by a recent report from Berke et al. ${ }^{34}$ in which they claimed to have observed substantial amounts of $\mathrm{Et}_{3} \mathrm{Si}$ $\mathrm{H} \rightarrow \mathrm{B}\left(\mathrm{C}_{6} \mathrm{~F}_{5}\right)_{3}$ in solution via ${ }^{29} \mathrm{Si}$ NMR spectroscopy at $233 \mathrm{~K}$. Noting, however, that their procedures did not appear to involve careful drying of the borane before use, it seemed likely that the peak assigned to this adduct is due in fact to $\mathrm{Et}_{3} \mathrm{SiOSiEt}_{3}$, formed rapidly when wet borane ${ }^{35,36}$ is treated with silane via rapid dehydrogenative silation of water. ${ }^{37,38}$ We confirmed this postulate by recording the ${ }^{29} \mathrm{Si}$ NMR spectrum of an authentic sample of $\mathrm{Et}_{3} \mathrm{SiOSiEt}_{3}$. Thus, this report of detection of the $\mathrm{Et}_{3} \mathrm{Si}-\mathrm{H} \rightarrow \mathrm{B}\left(\mathrm{C}_{6} \mathrm{~F}_{5}\right)_{3}$ adduct ${ }^{34}$ must be viewed as erroneous, and these species remain experimentally elusive.

In order to tilt the equilibrium $\mathrm{K}_{\mathrm{eq} 2}$ in favor of the borane silane adduct $\mathbf{I}$, the use of either a more Lewis basic silane or a more Lewis acidic borane might be contemplated. Since the latitude for increasing the Lewis basicity of the silane is rather narrow,${ }^{39}$ we have explored the latter strategy. To this end, we have utilized antiaromaticity in combination with perfluorination to prepare even more strongly Lewis acidic boranes than $\mathrm{B}\left(\mathrm{C}_{6} \mathrm{~F}_{5}\right)_{3}$. For example, we have shown 
that perfluoropentaphenylborole ${ }^{40}(\mathbf{V}$, Fig. 1, inset $)$ is an extremely Lewis acidic compound that binds $\mathrm{CO}^{41}$ and activates dihydrogen towards $\mathrm{H}-\mathrm{H}$ bond cleavage. ${ }^{42,43}$ In the latter reaction, an adduct of $\mathrm{H}_{2}$ with $\mathbf{V}$ is clearly implicated. Borole $\mathbf{V}$ also undergoes less well defined reactions with silanes that involve cleavage of the $\mathrm{Si}-\mathrm{H}$ bond, ${ }^{44}$ but due to the compound's low solubility in non-donor solvents, we have been unable to conduct low temperature spectroscopic studies aimed at detecting either an $\mathrm{H}_{2}$ or a silane adduct of $\mathbf{V}$. Accordingly, we recently reported the synthesis of 1,2,3-tris(pentafluorophenyl)-4,5,6,7-tetrafluoro-1-boraindene, ${ }^{45} \mathbf{1}$ (Fig. 1), a borane of essentially equal Lewis acid strength as $\mathbf{V}$, but substantially more soluble than $\mathbf{V}$ in typical inert solvents. Here we describe its behavior in the presence of triethylsilane, $\mathrm{Et}_{3} \mathrm{SiH}$, and fully demonstrate the viability of borane-silane adducts $\mathbf{I}$.

\section{Results and discussion}

The synthesis and characterization of boraindene $\mathbf{1}$ has been previously described. ${ }^{45}$ It is a red solid that retains this color in toluene solution; the color is due to a weak absorption in the visible at $465 \mathrm{~nm}\left(\varepsilon=900 \mathrm{M}^{-1} \mathrm{~cm}^{-1}\right.$, see Supplementary Fig. S1) that is due to a forbidden $\pi \rightarrow \mathrm{n}$ transition involving the empty p orbital on the Lewis acidic boron center. Upon complexation of a Lewis base, this absorption is disrupted and the color of the resulting adducts are pale yellow. Thus, Lewis acid/base adduct formation involving $\mathbf{1}$ is apparent with the naked eye by this red to yellow color change.

To explore the potential for adduct formation between 1 and $\mathrm{Et}_{3} \mathrm{SiH}\left(\mathrm{K}_{\mathrm{eq} 2}\right.$, Fig 2a), 1-2 equivalents of silane were added to a red solution of $\mathbf{1}$ in $d_{8}$-toluene. No visible change in color was observed at room temperature (Fig 2b) and little change to the components of the solution, as judged by ${ }^{19} \mathrm{~F}$ and ${ }^{1} \mathrm{H}$ NMR spectroscopy, was recorded. The thirteen separate resonances in 
the ${ }^{19} \mathrm{~F}$ NMR spectrum of $\mathbf{1}$ remained essentially unperturbed, while the signal for the Si- $H$ moiety in $\mathrm{Et}_{3} \mathrm{SiH}$ was a sharp septet at $3.79 \mathrm{ppm}$, essentially the same chemical shift as observed in pure samples of $\mathrm{Et}_{3} \mathrm{SiH}$. These observations showed that, while adduct formation was not favored under these conditions, boraindene $\mathbf{1}$ is stable towards reactions with silane that lead to ring opening processes observed for $\mathbf{V}$ and related compounds. ${ }^{44}$ Therefore, when a reversible red to yellow color change was evident upon cooling this solution to $195 \mathrm{~K}$ (Fig. 2b), the coordination of silane to the boraindene to form adduct $\mathbf{2}$ was strongly implicated. We therefore followed up this encouraging qualitative evidence with a detailed spectroscopic, structural and computational study, aimed at establishing thermodynamic parameters for the equilibrium $\mathrm{K}_{\mathrm{eq} 2}$ and characterizing borane/silane adduct 2.

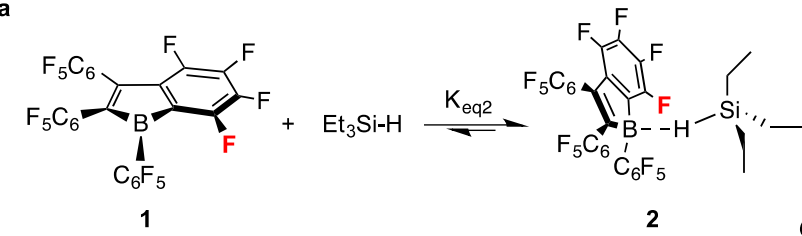

c

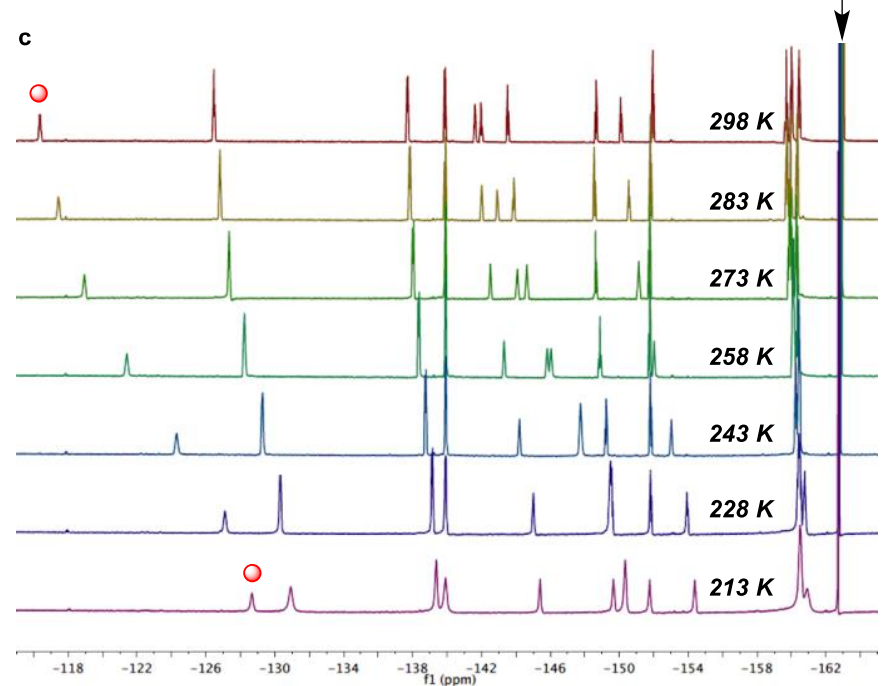

b

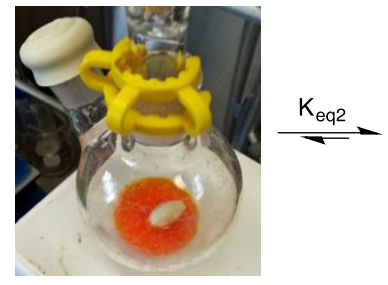

$298 K$

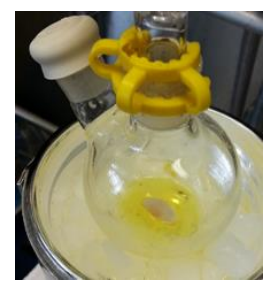

$195 K$

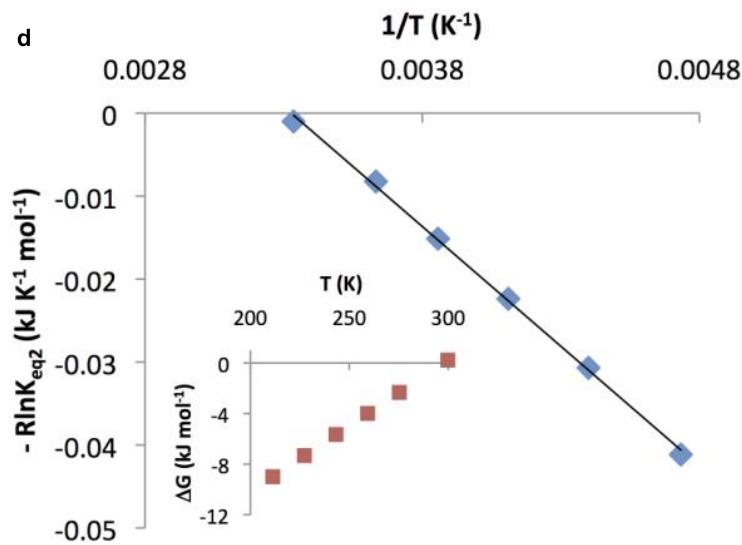

Figure 2. Equilibrium formation of borane-silane adduct 2. a, Schematic representation of adduct formation between 1,2,3-tris(pentafluorophenyl)-4,5,6,7-tetrafluoro-1-boraindene, 1, and triethylsilane, an example of equilibrium $\mathrm{K}_{\mathrm{eq} 2}$ as depicted in Fig. 1. b, Visible color change observed upon cooling solutions of $\mathbf{1}$ and $\mathrm{Et}_{3} \mathrm{SiH}$ from room temperature to $195 \mathrm{~K}$ with dry 
ice/acetone; upon warming the red color of 1 returns. c, Variable temperature ${ }^{19} \mathrm{~F}$ NMR spectra of this mixture, internally referenced to $\mathrm{C}_{6} \mathrm{~F}_{6}$, illustrating the significant perturbation in the chemical shift of the fluorine atom ortho to the boraindene boron atom (resonance marked by red circle). d, Van't Hoff analysis of the equilibrium, yielding thermodynamic parameters of $\Delta \mathrm{H}^{\circ}=$ $-29.7(3) \mathrm{kJ} \mathrm{mol}^{-1}$ and $\Delta \mathrm{S}^{\circ}=-100(1) \mathrm{J} \mathrm{mol}^{-1} \mathrm{~K}^{-1}$ for $\mathrm{K}_{\mathrm{eq} 2}$; inset gives a plot of $\Delta \mathrm{G}^{\circ} \mathrm{vs}$. temperature.

Variable temperature ${ }^{19} \mathrm{~F}$ NMR experiments were conducted on solutions of $\mathbf{1}$ with varying amounts of $\mathrm{Et}_{3} \mathrm{SiH}$ in $d_{8}$-toluene. As the temperature is lowered, most of the resonances in the ${ }^{19}$ F NMR spectrum shift slightly upfield, but the chemical shift for the fluorine ortho to boron on the boraindenyl core (colored red in Fig. 2a) is significantly perturbed as adduct formation is favored at lower temperatures (Fig. 2c). The drifting of this resonance is completely reversible as the temperature is lowered and raised. A similar phenomenon is observed in a series of ${ }^{19} \mathrm{~F}$ NMR spectra recorded at room temperature with varying amounts of excess silane added (Supplementary Fig. S2). Both experiments indicate that, as the equilibrium shifts towards the adduct $\mathbf{2}$, the chemical shift of the ortho fluorine atom moves closer to its absolute value in 2 . Since the position of the resonance for the ortho-F is a weighted average of the chemical shift of this fluorine in the free boraindene $\mathbf{1}$ and the adduct $\mathbf{2}$, this series of spectra can be utilized to extract the mole fraction of each species and evaluate the equilibrium constant $\mathrm{K}_{\mathrm{eq} 2 \text {. This was }}$ done by titrating $26 \mathrm{mM}$ solutions of 1 with measured amounts of added silane at six different temperatures. Treatment of this data using the binding isotherm equation allowed for determination of $\mathrm{K}_{\mathrm{eq} 2}$ at these temperatures (see Supplementary Fig. S3 and Table S1), facilitating a Van't Hoff analysis (Fig. 2d), which yields thermodynamic parameters of $\Delta \mathrm{H}^{\circ}=$ 29.7(3) $\mathrm{kJ} \mathrm{mol}^{-1}$ and $\Delta \mathrm{S}^{\circ}=-100(1) \mathrm{J} \mathrm{mol}^{-1} \mathrm{~K}^{-1}$ for $\mathrm{K}_{\mathrm{eq} 2}$. The enthalpy associated with silane binding is approximately double that calculated for the binding of $\mathrm{Et}_{3} \mathrm{SiH}$ to $\mathrm{B}\left(\mathrm{C}_{6} \mathrm{~F}_{5}\right)_{3}{ }^{25,33}$ but still rather weak, and the unfavorable entropic term renders the equilibrium approximately 
thermoneutral at room temperature (Fig. 2c, inset), completely consistent with our macroscopic and spectroscopic observations.

We depict the adduct as being bonded via a $\mathrm{Si}-\mathrm{H} \bullet \bullet \mathrm{B}$ bridge; this is consistent with computed structures for adducts involving $\mathrm{B}\left(\mathrm{C}_{6} \mathrm{~F}_{5}\right)_{3} .^{25,33}$ The variable temperature
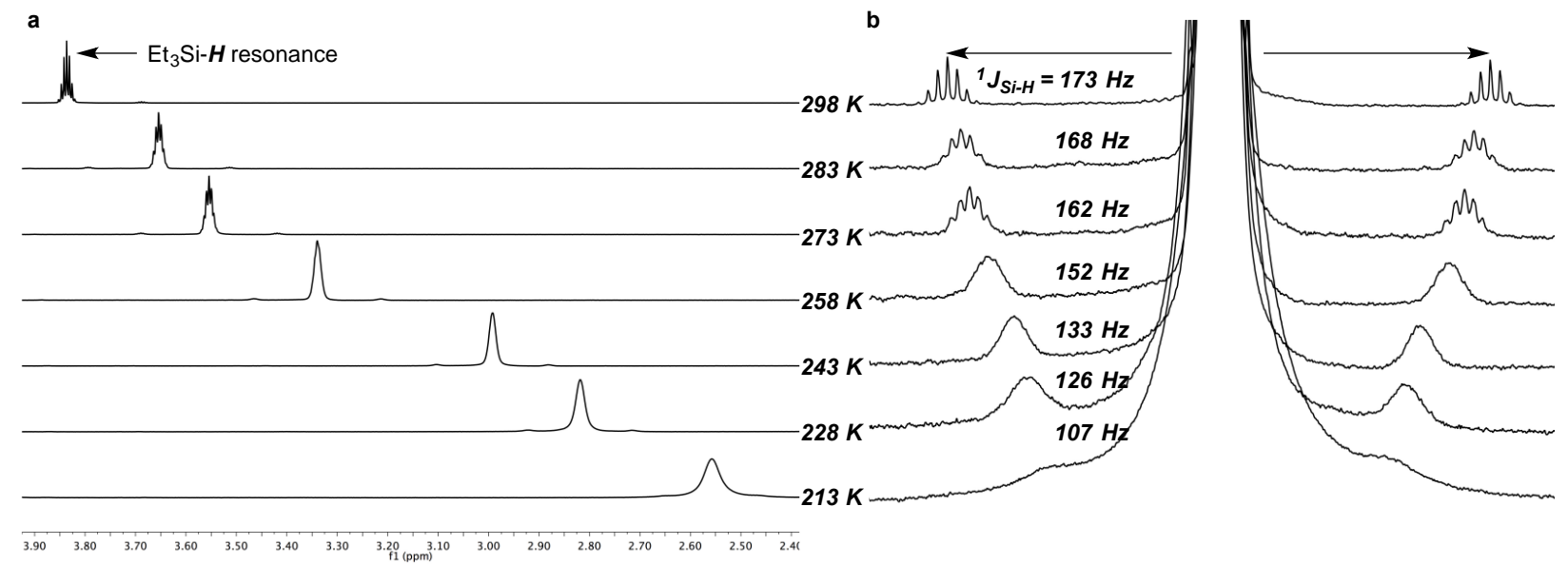

Figure 3. Partial proton NMR spectrum of solutions of 1 and Et3Si-H. a, Region of the spectrum showing the upfield shift for the $\mathrm{Si}-H$ resonance as the temperature is lowered and the equilibrium $\mathrm{K}_{\mathrm{eq} 2}$ favors adduct $\mathbf{2}$. b, Overlaid and expanded resonance showing the steady contraction in the one-bond silicon-hydrogen coupling constant as the shifts towards adduct 2.

${ }^{1} \mathrm{H}$ NMR and IR spectra for 2 provide experimental support for this assignment. As the temperature is lowered from 298 to $213 \mathrm{~K}$, the signal for the silane hydrogen in the ${ }^{1} \mathrm{H}$ NMR spectrum moves more than 1 ppm upfield (Fig. 3a). An expansion of this signal to render the

${ }^{29} \mathrm{Si}$ satellites visible shows clearly that, as the temperature is lowered and the equilibrium shifts towards 2 , the value for the ${ }^{1} \mathrm{~J}_{\mathrm{Si}-\mathrm{H}}$ coupling constant drops smoothly from $177 \mathrm{~Hz}$ in free $\mathrm{Et}_{3} \mathrm{Si}-\mathrm{H}$ to a value of $107(2) \mathrm{Hz}$ at $213 \mathrm{~K}$ (Fig 3b). A lowering of this coupling constant would be expected $^{46}$ as the $\mathrm{Si}-\mathrm{H}$ bond weakens upon interaction with the boron center. It was also anticipated that the stretching frequency of the $\mathrm{Si}-\mathrm{H}$ bond would be impacted upon adduct 
formation and indeed, a broad band at $1918 \mathrm{~cm}^{-1}$ is observed in solid samples of 2 precipitated from solutions of 1 in neat $\mathrm{Et}_{3} \mathrm{SiH}$ at $195 \mathrm{~K}$ (Supplementary Fig. 4a). The $v_{\mathrm{Si}-\mathrm{H}}$ stretch for free silane is a sharp band at $2103 \mathrm{~cm}^{-1}$; the broadness of the band in $\mathbf{2}$ is typical of such $v_{\mathrm{asSi}-\mathrm{H}-\mathrm{E}}$ moieties. ${ }^{47}$ Furthermore, when samples of $d_{1}-2$ are prepared using Et 3 Si-D, this band shifts from its position at $1918 \mathrm{~cm}^{-1}$ to $\approx 1400 \mathrm{~cm}^{-1}$ in the fingerprint region of the spectrum (Supplementary Fig. 4d).

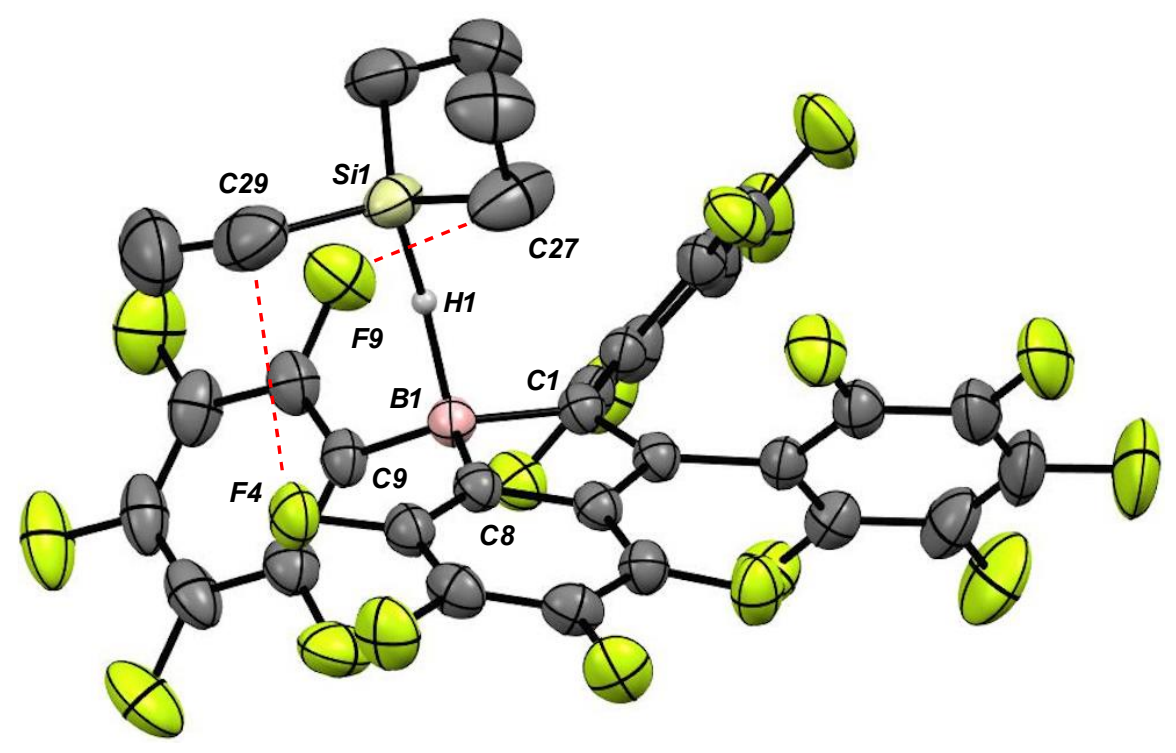

Figure 4. Crystal structure of boraindene-silane adduct 2 (50\% probability ellipsoids. Only the bridging hydrogen atom $\mathrm{H} 1$ is shown. Boron, silicon, carbon, fluorine and hydrogen atoms are in pink, light green, charcoal grey, lime green and grey, respectively. Red dashes indicate the close, non-bonded contacts. Selected bond lengths $(\AA)$, non-bonded distances $(\AA)$ and bond angles (deg): [calculated values]: $\mathrm{B} 1-\mathrm{C} 1=1.616(3)$ [1.607], B1-C $8=1.608(3)$ [1.594], B1-C9 = 1.605(3) [1.597], B1-H1 = 1.46(2) [1.402], Si1-H1 = 1.51(2) [1.608], F4-C29 = 3.262(2) [4.717], F9-C27 = 3.138(3) [3.171], C1-B1-C8 = 100.58(15) [100.91], C1-B1-C9 = 122.89(16) [121.061], C8-B1-C9 = 120.84(17) [122.57], B1-H1-Si1 = 157 [154.45].

The fact that we were able to perform IR spectroscopy on solid samples of $\mathbf{2}$ encouraged us to pursue the compound's crystallization for the purpose of structural analysis by X-ray diffraction. When neat $\mathrm{Et}_{3} \mathrm{SiH}$ was layered onto a toluene solution of boraindene 1 at $-35^{\circ} \mathrm{C}$ in a $5 \mathrm{~mm}$ glass 
tube and allowed to slowly diffuse together, X-ray quality crystals were obtained and the structure determined; a thermal ellipsoid depiction of the molecular structure is given in Fig. 4 along with selected metrical parameters. In $\mathbf{2}$, the silane binds the borane via the $\mathrm{Si}-\mathrm{H}$ bond, forming a somewhat bent $\mathrm{Si}(1)-\mathrm{H}(1)-\mathrm{B}(1)$ bridge $\left(157^{\circ}\right)$. The bridging hydrogen $\mathrm{H} 1$ was found and refined on the difference map, providing Si1-H1 and B1-H1 bond distances of 1.51(2) and 1.46(2) $\AA$, respectively. Thus, the hydrogen remains mainly associated with silicon, since typical Si-H distances are $\approx 1.48 \AA \AA^{46}$ while B-H distances in perfluoroaryl hydridoborate anions are around $1.14 \AA{ }^{48}$ and 2 can be viewed as a Lewis acid/base adduct rather than an ion pair of the form $\left[\mathrm{Et}_{3} \mathrm{Si}\right]^{+}\left[\mathrm{HB}\left(\mathrm{Ar}^{\mathrm{F}}\right)_{3}\right]^{-}$. Although the interaction is weak, the boron center is significantly pyramidalized relative to the planar boron in $1,{ }^{45}$ with the sum of the $\mathrm{C}-\mathrm{B}-\mathrm{C}$ angles amounting to $344.3(2)^{\circ}$. The adduct also appears stabilized by secondary $\mathrm{C}-\mathrm{H} \bullet \bullet \mathrm{F}$ Van der Waals interactions

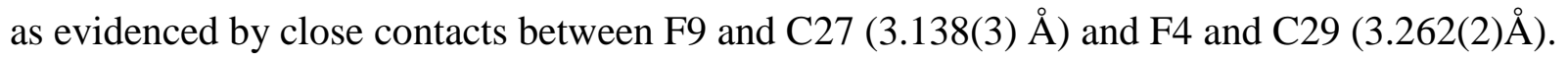

The adduct 2 was further studied by density functional theory (see Supplementary Information). Most of the optimized structural parameters of $\mathbf{2}$ correspond well with those in the crystal structure (Fig. 4, caption), but the calculated Si1-H1 bond length and the non-bonded distances between the $\mathrm{F}$ and $\mathrm{C}$ atoms are longer than in the $\mathrm{X}$-ray structure. This can be explained by the uncertainty in the location of the bridging hydrogen in the difference density map and crystal packing effects that are not accounted for in gas phase calculations. We note that an atoms-inmolecules analysis ${ }^{49}$ of the Si1-H1 bond critical point in $\mathbf{2}$ yields properties comparable to those for the Si-H bond in the free silane, indicating locally similar electronic structures. In contrast, the data for the B1-H1 bond critical point in $\mathbf{2}$ differ considerably from results obtained for the anion $\left[\mathrm{HB}\left(\mathrm{C}_{6} \mathrm{~F}_{5}\right)_{3}\right]^{-}$, which supports the view of $\mathbf{2}$ as a Lewis acid/base adduct. The calculated 
enthalpy associated with silane binding, $\Delta \mathrm{H}^{\circ}$ calc, is $-21 \mathrm{~kJ} \mathrm{~mol}^{-1}$ which is in agreement with the value obtained from the Van't Hoff analysis; the corresponding $\Delta \mathrm{G}_{\text {calc }}^{\circ}$ is $32 \mathrm{~kJ} \mathrm{~mol}^{-1}$.

To probe the stability of $\mathbf{2}$ further, calculations were carried out to compare the bonding in $\mathbf{2}$ to that in the $\mathrm{Et}_{3} \mathrm{SiH}$ adduct with $\mathrm{B}\left(\mathrm{C}_{6} \mathrm{~F}_{5}\right)_{3}$ (i.e., I, Fig. 1) and in the hypothetical adduct with perfluoroarylborole V (denoted VI). The calculated enthalpies and Gibbs energies (Table 1) show that adduct $\mathbf{I}$ is clearly the weakest of the three, while adduct VI is predicted to be as strongly bound as $\mathbf{2}$. A further decomposition of the borane-silane bonding interaction allows quantification of the energy components arising from distortion of fragment geometries $\left(\Delta E_{\text {dist }}\right)$ and electronic (bonding) effects that stabilize the adducts ( $\left.\Delta E_{\text {inst }}\right)$. Adduct $\mathbf{I}$ has the smallest distortion energy but is nevertheless the least bound due to its weakest bonding interaction. While the distortion energies in $\mathbf{2}$ and, in particular, VI are greater than in $\mathbf{I}$, the difference is more than compensated by stronger bonding interactions between the boraindene/borole and silane. The data in Table 1 also suggests that the Lewis-acidity of the investigated boranes decreases in the series $\mathbf{V}>\mathbf{1}>\mathrm{B}\left(\mathrm{C}_{6} \mathrm{~F}_{5}\right)_{3}$, a notion corroborated by calculated hydride affinities of $-593,-564$ and $-538 \mathrm{~kJ} \mathrm{~mol}^{-1}$, respectively. Thus, a fine balance between steric and electronic effects, rather than the high Lewis acidity of $\mathbf{1}$ alone, explain the stability of the adduct $\mathbf{2}$.

Table 1 The calculated bonding enthalpies $\left(\Delta \mathrm{H}^{\circ}\right.$ calc $)$, Gibbs energies $\left(\Delta \mathrm{G}^{\circ}\right.$ calc $)$, distortion energies $\left(\Delta \mathrm{E}_{\text {dist }}\right)$ and instantaneous interaction energies $\left(\Delta \mathrm{E}_{\text {inst }}\right)$ of the adducts $\mathbf{2}$, I and VI. ${ }^{a, b}$

\begin{tabular}{ccccc}
\hline adduct & $\Delta \mathrm{H}^{\circ}$ calc & $\Delta \mathrm{G}_{\text {calc }}^{\circ}$ & $\Delta \mathrm{E}_{\text {dist }}$ & $\Delta \mathrm{E}_{\text {inst }}$ \\
\hline $\mathbf{2}$ & -21 & 32 & 75 & -102 \\
$\mathbf{I}$ & -6 & 56 & 68 & -79 \\
VI & -20 & 42 & 103 & -129 \\
\hline
\end{tabular}

${ }^{a}$ Energies are given in $\mathrm{kJ} \mathrm{mol}^{-1} .{ }^{b}$ The sum of $\Delta \mathrm{E}_{\text {dist }}$ and $\Delta \mathrm{E}_{\text {inst }}$ equals $\Delta \mathrm{H}_{\text {calc }}$ at $0 \mathrm{~K}$ temperature. 
The characterization of $\mathbf{2}$ in both solution and the solid state represents the first direct evidence for the long-proposed activation of silane by perfluoroarylboranes. ${ }^{7}$ While intramolecular Si$\mathrm{H} \bullet \mathrm{B}$ interactions have been noted, ${ }^{50}$ the intermolecular silane borane adduct $\mathbf{2}$ is explicitly relevant to metal-free, "frustrated Lewis pair" ${ }^{20}$ mediated hydrosilations of unsaturated functions. To demonstrate that adduct $\mathbf{2}$ reacts in ways that are consistent with the mechanistic proposals of Fig. 1, we examined its reactivity towards a simple nucleophile and tested the efficacy of $\mathbf{1}$ as a catalyst for the hydrosilation of olefins (Fig. 5). When boraindene $\mathbf{1}$ and silane were dissolved in toluene and cooled to $-78^{\circ} \mathrm{C}$, one equivalent of dry bis-(triphenylphosphine)iminium chloride, $[\mathrm{PPN}]^{+}[\mathrm{Cl}]^{-}$, was added to form, immediately and quantitatively, the $[\mathrm{PPN}]^{+}$salt of the hydridoborate anion, 3, and $\mathrm{Et}_{3} \mathrm{SiCl}$ (Fig. 5a). The latter was identified by comparison with an authentic sample, while 3 exhibited ${ }^{11} \mathrm{~B}$ NMR $(-16.2 \mathrm{ppm})$ and ${ }^{1} \mathrm{H}$ NMR $\left(1.6 \mathrm{ppm},{ }^{1} \mathrm{~J}_{\mathrm{BH}}=90 \mathrm{~Hz}\right)$ data consistent with formation of a hydridoborate. ${ }^{48}$ The chloroborate $\mathbf{4}$ that might be expected to form competitively (Fig. 5a) was not observed; this was confirmed by synthesizing it separately from $\mathbf{1}$ and $[\mathrm{PPN}]^{+}[\mathrm{Cl}]^{-}$. Furthermore, a control experiment in which $\mathbf{4}$ was treated with excess $\mathrm{Et}_{3} \mathrm{SiH}$ showed that this is not a viable pathway to 3 . In fact, when the boraindene $1 / \mathrm{Et}_{3} \mathrm{SiH}$ mixture is treated with $[\mathrm{PPN}]^{+}[\mathrm{Cl}]^{-}$at room temperature, the hydridoborate 3 is the exclusive boron containing product. From equilibrium thermodynamic data, under these conditions, the speciation of $\mathbf{2}$ in solution is less than 5\% relative to free boraindene $\mathbf{1}$, suggesting that the borane silane adduct reacts with chloride ion at least 20 times faster than the free boraindene. On the face of it, this seems quite surprising, but is in line with the high rates hydrosilation of imine and carbonyl functions by $\mathrm{B}\left(\mathrm{C}_{6} \mathrm{~F}_{5}\right)_{3}$; clearly, these borane silane adducts are highly reactive towards nucleophiles. 

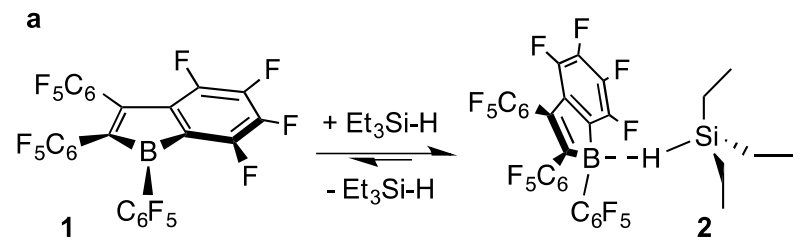

b

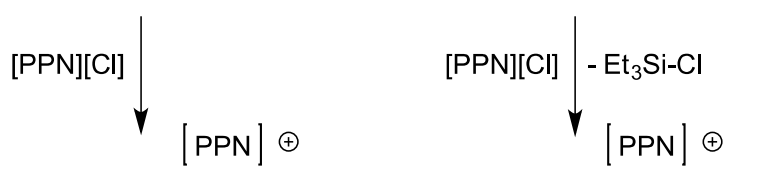

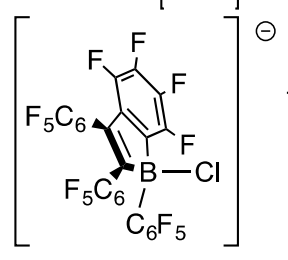

4

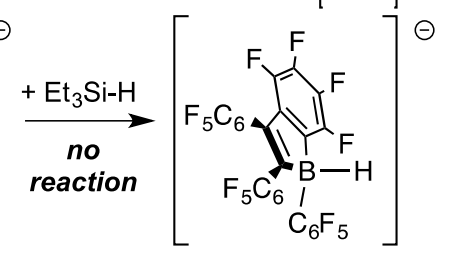

3

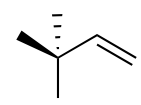<smiles>C=C(Pc1ccccc1)c1ccccc1</smiles><smiles>C1=CCCCC1</smiles>

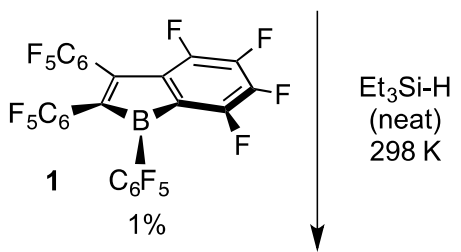<smiles>CC[SiH2]CCC(C)C</smiles><smiles>CC[Si]CC(c1ccccc1)c1ccccc1</smiles>

$1 \mathrm{hr}, 100 \%$<smiles>CC[SiH2]C1CCCCC1</smiles>

$6 \mathrm{hr}, 95 \%$

Figure 5. Reactivity of boraindene silane adduct 2. a, Schematic representation of the reactivity of both 1 and $\mathbf{2}$ with PPN chloride. b, Catalytic hydrosilation of the olefins tert-butyl ethylene, 1,1-diphenylethylene and cyclohexene by boraindene 1 using $\mathrm{Et}_{3} \mathrm{SiH}$; yields given are estimated by NMR spectroscopy.

The scope and utility of boraindene $\mathbf{1}$ as a hydrosilation or hydrogenation ${ }^{45}$ catalyst is under active investigation, but initial results indicate that it is highly active for the hydrosilation of olefins that lack polar functionalities. Gevorgyan and co-workers demonstrated in 2002 that $\mathrm{B}\left(\mathrm{C}_{6} \mathrm{~F}_{5}\right)_{3}$ is active for such hydrosilations, albeit at high catalyst loadings (10 mol \%) and long reaction times (> 10 hours). ${ }^{9}$ As shown in Fig. 5b, boraindene $\mathbf{1}$ is a highly active catalyst for the hydrosilation of tert-butyl ethylene, 1,1-diphenyl ethylene and cyclohexene using $\mathrm{Et}_{3} \mathrm{SiH}$ at loadings of only $1 \mathrm{~mol} \%$. The reactions are carried out in neat silane at room temperature and are complete in 1-6 hours. Qualitatively, boraindene $\mathbf{1}$ is a more active catalyst for this reaction than $\mathrm{B}\left(\mathrm{C}_{6} \mathrm{~F}_{5}\right)_{3}$, presumably because of the more favorable equilibrium constant $\mathrm{K}_{\mathrm{eq} 2}$ for boranesilane adduct formation in $\mathbf{1}$ vs $\mathrm{B}\left(\mathrm{C}_{6} \mathrm{~F}_{5}\right)_{3}$. 


\section{Methods}

1,2,3-tris(pentafluorophenyl)-4,5,6,7-tetrafluoro-1-boraindene 1 was prepared as described elsewhere46; triethylsilane was purchased from Sigma-Aldrich and dried via distillation under vacuum from calcium hydride. Unless explicitly stated otherwise, all operations were carried out under a purified argon atmosphere using either inert-atmosphere-glovebox or vacuum-line techniques. Dichloromethane was dried over and distilled from $\mathrm{CaH} 2$, then distilled from molecular sieves after at least three days. Toluene, hexanes and benzene were dried over and distilled from sodium/benzophenone. Argon was passed through a Matheson TriGas cartridge (model M641-02) prior to use to remove traces of water and oxygen. All NMR analyses (1H, $13 \mathrm{C}\{1 \mathrm{H}\}$ DEPT-Q, 11B, 19F, 31P) were performed on either a Bruker $400 \mathrm{MHz}$ or $600 \mathrm{MHz}$ instrument. The X-ray crystallography analysis was performed on suitable crystals coated in Paratone oil and mounted on a Bruker Smart APEX II with a three-circle diffractometer. Full descriptions of the methods used for data accumulation and analysis, as well as representative NMR and infrared spectra and computational results, are given in the Supplementary Information.

\section{Acknowledgements}

Funding for the experimental work described was provided by the Natural Sciences and Engineering Research Council of Canada in the form of a Discovery Grant to W.E.P. Funding for the computational work described was provided by the Academy of Finland in the form of a Research Grant and Fellowship to H.M.T. 


\section{Author contributions}

A.Y.H. and W.E.P. conceived and designed the experiments, A.Y.H. performed the experiments, and determined the X-ray structure, H.M.T. and A.M. conceived and designed the computational work, J.H. and A.M. executed the calculations and performed data analyses. A.Y.H., W.E.P. and A.M. co-wrote the paper with input from J.H. and H.M.T.

\section{Additional information}

The authors declare no competing financial interests. Supplementary information and chemical compound information accompany this paper at www.nature.com/naturechemistry. Reprints and permission information is available online at http://npg.nature.com/reprintsandpermissions/. Correspondence and requests for materials should be addressed to W.E.P.

\section{References}

1 Hartwig, J. F. Organotransition Metal Chemistry - From Bonding to Catalysis. (University Science Books, 2010).

2 Bullock, R. M. Abundant Metals Give Precious Hydrogenation Performance. Science 342, 1054-1055 (2013).

3 Frey, G. D., Lavallo, V., Donnadieu, B., Schoeller, W. W. \& Bertrand, G. Facile Splitting of Hydrogen and Ammonia by Nucleophilic Activation at a Single Carbon Center. Science 316, 439-441 (2007).

4 Welch, G. C., Juan, R. R. S., Masuda, J. D. \& Stephan, D. W. Reversible, Metal-Free Hydrogen Activation. Science 314, 1124-1126 (2006).

5 Spikes, G. H., Fettinger, J. C. \& Power, P. P. Facile Activation of Dihydrogen by an Unsaturated Heavier Main Group Compound. J. Am. Chem. Soc. 127, 12232-12233 (2005).

6 Massey, A. G., Park, A. J. \& Stone, F. G. A. Proc. Chem. Soc., 212 (1963).

7 Parks, D. J. \& Piers, W. E. Tris(pentafluorophenyl)boron-catalyzed hydrosilation of aromatic aldehydes, ketones, and esters. J. Am. Chem. Soc. 118, 9440-9441 (1996).

8 Blackwell, J. M., Sonmor, E. R., Scoccitti, T. \& Piers, W. E. B(C6F5)(3)-catalyzed hydrosilation of imines via silyliminium intermediates. Org. Lett. 2, 3921-3923 (2000).

9 Rubin, M., Schwier, T. \& Gevorgyan, V. Highly Efficient B(C6F5)3-Catalyzed Hydrosilylation of Olefins. J. Org. Chem. 67, 1936-1940 (2002).

10 Blackwell, J. M., Morrison, D. J. \& Piers, W. E. B(C6F5)(3) catalyzed hydrosilation of enones and silyl enol ethers. Tetrahedron 58, 8247-8254 (2002). 
11 Berkefeld, A., Piers, W. E. \& Parvez, M. Tandem Frustrated Lewis

Pair/Tris(pentafluorophenyl)borane-Catalyzed Deoxygenative Hydrosilylation of Carbon Dioxide. J. Am. Chem. Soc. 132, 10660-10661 (2010).

12 Müther, K., Mohr, J. \& Oestreich, M. Silylium Ion Promoted Reduction of Imines with Hydrosilanes. Organometallics 32, 6643-6646 (2013).

13 Chen, D., Leich, V., Pan, F. \& Klankermayer, J. Enantioselective Hydrosilylation with Chiral Frustrated Lewis Pairs. Chem. Eur. J. 18, 5184-5187 (2012).

14 Chase, P. A., Welch, G. C., Jurca, T. \& Stephan, D. W. Metal-Free Catalytic Hydrogenation. Angew. Chem. Int. Ed. 46, 8050-8053 (2007).

15 Chase, P. A., Jurca, T. \& Stephan, D. W. Lewis acid-catalyzed hydrogenation: $\mathrm{B}(\mathrm{C} 6 \mathrm{~F} 5) 3-$ mediated reduction of imines and nitriles with H2. Chem. Commun., 17011703 (2008).

16 Chernichenko, K. et al. A frustrated-Lewis-pair approach to catalytic reduction of alkynes to cis-alkenes. Nat Chem 5, 718-723 (2013).

17 Parks, D. J., Piers, W. E., Parvez, M., Atencio, R. \& Zaworotko, M. J. Synthesis and solution and solid-state structures of tris(pentafluorophenyl)borane adducts of $\mathrm{PhC}(\mathrm{O}) \mathrm{X}$ (X = H, Me, OEt, NPr2i). Organometallics 17, 1369-1377 (1998).

18 Blackwell, J. M., Piers, W. E., Parvez, M. \& McDonald, R. Solution and solid-state characteristics of imine adducts with tris(pentafluorophenyl)borane. Organometallics 21, 1400-1407 (2002).

19 Parks, D. J., Blackwell, J. M. \& Piers, W. E. Studies on the mechanism of B(C6F5)(3)catalyzed hydrosilation of carbonyl functions. J. Org. Chem. 65, 3090-3098 (2000).

20 Stephan, D. W. "Frustrated Lewis pairs"; a concept for new reactivity and catalysis. Org. Biomol. Chem. 6, 1535-1539 (2008).

21 Stephan, D. W. \& Erker, G. Frustrated Lewis Pairs: Metal-free Hydrogen Activation and More. Angew. Chem. Int. Ed. 49, 46-76 (2010).

22 Piers, W. E., Marwitz, A. J. V. \& Mercier, L. G. Mechanistic Aspects of Bond Activation with Perfluoroarylboranes. Inorg. Chem. 50, 12252-12262 (2011).

23 Grimme, S., Kruse, H., Goerigk, L. \& Erker, G. The Mechanism of Dihydrogen Activation by Frustrated Lewis Pairs Revisited. Angew. Chem. Int. Ed. 49, 1402-1405 (2010).

24 Rokob, T. A., Bakó, I., Stirling, A., Hamza, A. \& Pápai, I. Reactivity Models of Hydrogen Activation by Frustrated Lewis Pairs: Synergistic Electron Transfers or Polarization by Electric Field? J. Am. Chem. Soc. 135, $4425-4437$ (2013).

25 Sakata, K. \& Fujimoto, H. Quantum Chemical Study of B(C6F5)3-Catalyzed Hydrosilylation of Carbonyl Group. J. Org. Chem. 78, 12505-12512 (2013).

26 Rendler, S. \& Oestreich, M. Conclusive Evidence for an SN2-Si Mechanism in the B(C6F5)3-Catalyzed Hydrosilylation of Carbonyl Compounds: Implications for the Related Hydrogenation. Angew. Chem. Int. Ed. 47, 5997-6000 (2008).

27 Hog, D. T. \& Oestreich, M. B(C6F5)3-Catalyzed Reduction of Ketones and Imines Using Silicon-Stereogenic Silanes: Stereoinduction by Single-Point Binding. Eur. J. Org. Chem. 2009, 5047-5056 (2009).

28 Hermeke, J., Mewald, M. \& Oestreich, M. Experimental Analysis of the Catalytic Cycle of the Borane-Promoted Imine Reduction with Hydrosilanes: Spectroscopic Detection of Unexpected Intermediates and a Refined Mechanism. J. Am. Chem. Soc. 135, 1753717546 (2013). 
29 Marwitz, A. J. V., Dutton, J. L., Mercier, L. G. \& Piers, W. E. Dihydrogen Activation with tBu3P/B(C6F5)3: A Chemically Competent Indirect Mechanism via in SituGenerated p-tBu2P-C6F4-B(C6F5)2. J. Am. Chem. Soc. 133, 10026-10029 (2011).

30 Parks, D. J., Piers, W. E. \& Yap, G. P. A. Synthesis, Properties, and Hydroboration Activity of the Highly Electrophilic Borane Bis(pentafluorophenyl)borane, HB(C6F5)21. Organometallics 17, 5492-5503 (1998).

31 Nikonov, G. I., Vyboishchikov, S. F. \& Shirobokov, O. G. Facile Activation of H-H and Si-H Bonds by Boranes. J. Am. Chem. Soc. 134, 5488-5491 (2012).

32 Parks, D. J., von H. Spence, R. E. \& Piers, W. E. Bis(pentafluorophenyl)borane: Synthesis, Properties, and Hydroboration Chemistry of a Highly Electrophilic Borane Reagent. Angew. Chem. Int. Ed. Engl. 34, 809-811 (1995).

33 Chojnowski, J. et al. Mechanism of the B(C6F5)3-Catalyzed Reaction of Silyl Hydrides with Alkoxysilanes. Kinetic and Spectroscopic Studies. Organometallics 24, 6077-6084 (2005).

34 Jiang, Y. et al. The "Catalytic Nitrosyl Effect": NO Bending Boosting the Efficiency of Rhenium Based Alkene Hydrogenations. J. Am. Chem. Soc. 135, 4088-4102 (2013).

35 Bergquist, C. et al. Aqua, Alcohol, and Acetonitrile Adducts of Tris(perfluorophenyl)borane:, Äâ Evaluation of $\mathrm{Br} \sqrt{ } \prod$ nsted Acidity and Ligand Lability with Experimental and Computational Methods. J. Am. Chem. Soc. 122, 10581-10590 (2000).

36 Beringhelli, T., Maggioni, D. \& D'Alfonso, G. 1H and 19F NMR Investigation of the Reaction of B(C6F5)3 with Water in Toluene Solution. Organometallics 20, 4927-4938 (2001).

37 Blackwell, J. M., Foster, K. L., Beck, V. H. \& Piers, W. E. B(C6F5)(3)-catalyzed silation of alcohols: A mild, general method for synthesis of silyl ethers. J. Org. Chem. 64, 48874892 (1999).

38 Gevorgyan, V., Rubin, M., Benson, S., Liu, J.-X. \& Yamamoto, Y. A Novel B(C6F5)3Catalyzed Reduction of Alcohols and Cleavage of Aryl and Alkyl Ethers with Hydrosilanes, Ä†. J. Org. Chem. 65, 6179-6186 (2000).

39 Richter, D., Tan, Y., Antipova, A., Zhu, X.-Q. \& Mayr, H. Kinetics of Hydride Abstractions from 2-Arylbenzimidazolines. Chemistry - An Asian Journal 4, 1824-1829 (2009).

40 Fan, C., Piers, W. E. \& Parvez, M. Perfluoropentaphenylborole. Angew. Chem. Int. Ed. 48, 2955-2958 (2009).

41 Fukazawa, A. et al. Reaction of pentaarylboroles with carbon monoxide: an isolable organoboron carbonyl complex. Chemical Science 3, 1814-1818 (2012).

42 Fan, C., Mercier, L. G., Piers, W. E., Tuononen, H. M. \& Parvez, M. Dihydrogen Activation by Antiaromatic Pentaarylboroles. J. Am. Chem. Soc. 132, 9604-9606 (2010).

43 Houghton, A. Y., Karttunen, V. A., Fan, C., Piers, W. E. \& Tuononen, H. M. Mechanistic Studies on the Metal-Free Activation of Dihydrogen by Antiaromatic Pentarylboroles. $J$. Am. Chem. Soc. 135, 941-947 (2012).

44 Braunschweig, H., Damme, A., Hörl, C., Kupfer, T. \& Wahler, J. Si-H Bond Activation at the Boron Center of Pentaphenylborole. Organometallics 32, 6800-6803 (2013).

45 Houghton, A. Y., Karttunen, V. A., Piers, W. E. \& Tuononen, H. M. Hydrogen activation with perfluorinated organoboranes: 1,2,3-tris(pentafluorophenyl)-4,5,6,7-tetrafluoro-1boraindene. Chem. Commun. 50, 1295-1298 (2014). 
46 Corey, J. Y. \& Braddock-Wilking, J. Reactions of Hydrosilanes with Transition-Metal Complexes: Formation of Stable Transition-Metal Silyl Compounds. Chem. Rev. 99, 175-292 (1998).

47 Nava, M. \& Reed, C. A. Triethylsilyl Perfluoro-Tetraphenylborate, [Et3Si+][F20-BPh4], a Widely Used Nonexistent Compound. Organometallics 30, 4798-4800 (2011).

48 Berkefeld, A. et al. Carbon Monoxide Activation via O-Bound CO Using Decamethylscandocinium-Hydridoborate Ion Pairs. J. Am. Chem. Soc. 134, 10843-10851 (2012).

49 Bader, R. F. W. Atoms in Molecules: A Quantum Theory., (Oxford University Press, 1990).

50 Wrackmeyer, B., Milius, W. \& Tok, O. L. Reaction of Alkyn-1-yl(diorganyl)silanes with 1-Boraadamantane: Si-H-B Bridges Confirmed by the Molecular Structure in the Solid State and in Solution. Chem. Eur. J. 9, 4732-4738 (2003). 